\title{
ALGUMAS CONSIDERAÇÕES SOBRE O CONSUMO DE ALIMENTOS EM ICAPARA E PONTAL DE RIBEIRA, SÃO PAULO, BRASIL *
}

Rosa Nilda Mazzilli *:

RSPU-B $/ 247$

Mazzilli, R. N. - Algumas considerações sobre o consumo de alimentos em Icapara e Pontal de Ribeira, São Paulo, Brasil. Rev. Saúde públ., S. Paulo, 9:49-55, 1975 .

Rescmo: O inquérito atimentar realizado em 105 familias de Icapara $\epsilon$ 56 de Pontal revelou algumas deficiencias alimentares, decorrentes das falhas existentes em sua alimentacão habitual. O consumo alimentar de 24 horas for obtido atraiés do método da pesagem direta dos alimentos, combinado com o recordatório. Os alimentos de maior consumo, considerados básicos, foram a farinha de mandioca, o peixe e o arroz. A inadequação da dieta em determinados nutrientes, como as vitaminas $A, B_{1}, B_{2}$ e $C$ e o cálcio está ligada aos habitos alimentares: o leite, as hortalicas e as frutas não são expressivas na alimentação diária dessas populações. A proteina animal não representou problema nessas comunidades, pois o consumo médlo diário de pelxe fol alto. Un programa integrado de Educaçāo Nutricional e Santária, aproveitando e desenvoliendo os recursos locais, será fundamental nessa área no sentido de melhorar os padróes alimentar e social dessas populacooses.

UNITERMos: Inquérito alimentar. Alimentos, consumo. Icapara, SP (Brasil). Pontal de Ribeira. SP (Brasil).

Segundo Stare" a nutrição é um dos fatores ambientais mais importantes para garantir o hem estar das pessoas. conceito esse defendido também pela OMS. Como parte desse bem estar. inclui-se a saúde do indivíduo e esta. por sua rez. está estreitamente relacionada com os seus hábitos alimentares. O conhecimento do consumo de alimentos e dos hábitos alimentares das populações é de fundamental importância para que se evidenciem as neces- sidades e deficiências relativas à sua alimentação. Conhecer a disponibilidade dos recursos locais. especialmente no que se refere aos alimentos regionais. e dos padrôes culturais constituem aspectos preponderantes no estado nutricional das pessoas.

$O$ conhecimento do consumo de alimentos e dos hábitos alimentares constitui auxílio valioso no combate à desnutrição, problema que cada dia mais preocupa as autoridades do país.

Trabalho realizado como parte do programado Departamento de Nutriçăo e do Serviço de Vale do Ribeira latualmente SLDELPA, Trabalho apresentado no XIII Congresso Brasileiro de Higiene, SP, 1970.

* Nutricionista do Departamento de Nutrição da Faculdade de Saúde Pública da Universıdade de são Paulo. 
MAZZILLI, R.N. - Algumas consideracôes sobre o consumo de alimentos em Icapara e Pontal de Ribeira, São Paulo, Brasil. Rev. Saúde públ., S. Paulo, 9:49-55, 1975.

Com o objetivo de conhecer o consumo de alimentos e os hábitos alimentares da população das vilas de Icapara e de Pontal do Ribeira, realizou-se o presente estudo, contando com a colaboração de nutricionistas do Departamento de Nutrição e dos alunos do 3.० Ano do Curso de Graduação de Nutricionistas da Faculdade de Saúde Pública, da Ĺniversidade de São Paulo.

Essas comunidades pertencem ao Vale do Ribeira, litoral sul do Estado de São Paulo, Brasil, distando, aproximadamente, $160 \mathrm{~km}$ da capital ${ }^{1}$. A população dessas vilas é estável, sendo autóctones quase a totalidade dos habitantes. São estes de baixo nível sócio-econômico e cultural, e têm como fonte principal de renda a pesca. para a qual ainda são utilizadas técnicas rudimentares.

A agricultura é praticamente a da subsistência, empregando métodos primitivos de cultura. O solo é arenoso, de baixa fertilidade, A principal cultura é a da mandioca, consumida sob a forma de farinha, a qual representa o alimento básico da região. $\mathrm{O}$ arroz é o $2 .^{\circ}$ produto cultivado, sendo o seu consumo inferior ao da farinha de mandioca.

A maior parte das casas é de madeira, sem pintura, com piso de tábua ou de terra batida e cobertas com telhas de barro. Geralmente as casas possuem um pequeno jardim. A vegetação local é exuberante, mas, praticamente, sem valor para a alimentação.

\section{CAsutstica E Metodos}

Visando obter dados sobre o consumo de alimentos, foi realizado o inquérito alimentar em 105 famílias de Icapara e 56 de Pontal do Ribeira, que constituíam a totalidade de suas populações*.

Empregou-se, na coleta de dados, o método da pesagem direta dos alimentos, combinado com o recordatório. Obteve-se o consumo alimentar de 24 horas de cada família, cobrindo-se o período de uma semana em cada comunidade, procedimento esse que permitiu avaliar também a variação semanal da alimentação naquelas localidades.

\section{RESLITADOS}

As quantidades médias dos alimentos consumidos por dia e por pessoa, bem como o número e a percentagem de famílias que utilizaram cada alimento, são apresentadas na Tabela 1.

Os alimentos relacionados na Tabela 1 foram reunidos em 10 grupos para facilitar a avaliação dos hábitos alimentares.

0 consumo médio diário, as recomendações diárias por pessoa e as percentagens de adequação para os vários nutrientes são apresentados nas Tabelas 2 e 3 .

\section{COM TINTARIOS}

Analisando-se a Tabela 1, verifica-se que os grupos 2 (carnes), 5 (cereais) e 8 (gorduras) são os de uso mais frequiente, consumidos pela quase totalidade da população das duas comunidades estudadas.

No grupo 2 salienta-se o peixe, de uso generalizado, alimento básico naquela região. Embora constituindo o peixe um alimento habitual da refeição diária, a sua ingestão se restringia aos indivíduos maiores de 4 anos, existindo o tabu de que o peixe era alimento quente $\mathrm{e}$, portanto, prejudicional às crianças. Para os demais tipos de carne, o consumo foi, entretanto, insignificante. Ainda que muitas famílias possuissem criação de galinhas, não houve consumo de carne de aves. $O$ uso dos ovos também foi muito reduzido: das 160 famílias investigadas nas duas localidades, somente 2 delas os incluiram em suas refeiçōes.

* Dados levantados pelo Departamento de Nutrição em 1969. 
MIAZZILli. R.N. - Algumas consideraçóes sobre o consumo de alimentos em Icapara e Pontal de Ribeira, São Paulo, Brasil. Rer. Saíle pribl., S. Paulo, 9:49-55, 1975.

T A BELA 1

Per-capita médio diário de alimentos de Icapara e Pontal do Ribeira

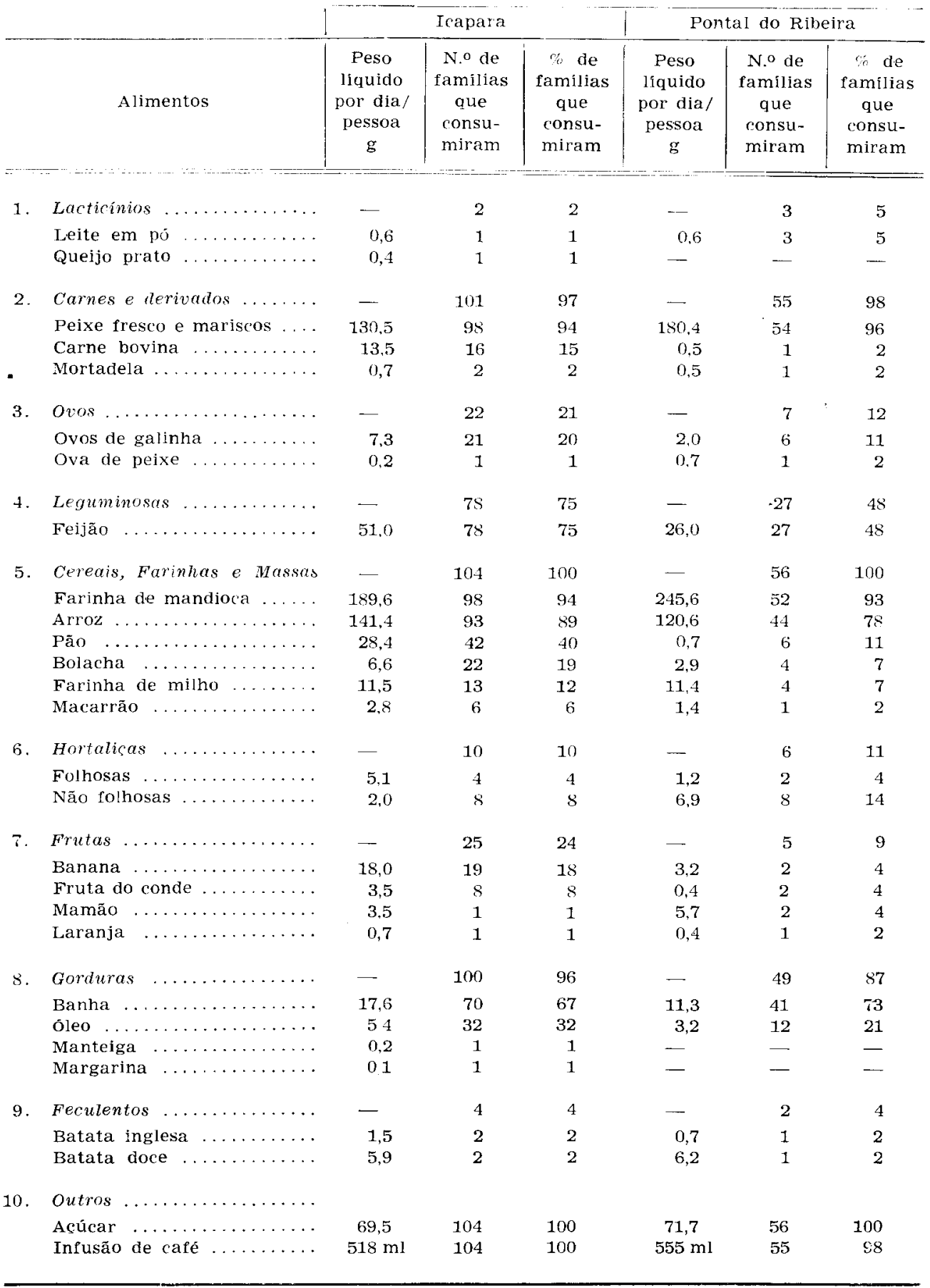


MAZZILLI, R.N. - Algumas consideraçōes sobre o consumo de alimentos em Icapara e Pontal de Ribeira, São Paulo, Brasil. Rev. Saúde públ., S. Paulo, 9:49-55, 1975.

T A B E L A 2

Consumo médio diário, necessidade média diária por pessoa e porcentagem de adequasão para os vários nutrientes na Vila de Icapara *

\begin{tabular}{l|c|c|c}
\hline Nutrientes & $\begin{array}{c}\text { Consumo médio } \\
\text { diário por pessoa }\end{array}$ & $\begin{array}{c}\text { Necessidade média } \\
\text { diária por pessoa }\end{array}$ & $\begin{array}{c}\text { Porcentagem de } \\
\text { adequacão }\end{array}$ \\
\hline Calorias & 2189 & 2177 & 100 \\
Proteínas g & 62 & 50 & 123 \\
Vitamina A meg & 133 & 1321 & 10 \\
Vitamina C mg & 31 & 50 & 62 \\
Niacina mg & 12,6 & 14,4 & 87 \\
Vitamina B $\mathrm{mg}$ & 0.8 & 1,3 & 81 \\
Vitamina B $\mathrm{mg}$ & 0,9 & 1,1 & 21 \\
Cálcio mg & 197 & 916 & 101 \\
Fósforo mg & 926 & 915 & 85 \\
Ferro mg & 11,2 & 13,2 & \\
\hline
\end{tabular}

Dados baseados nas Tabelas do US National Academy of Science' 1 e da Faculdade de Saúde Pública da USP' ${ }^{5}$

TABELA 3

Consumo médio diário, necessidade média diária por pessoa e porcentagem de adequação para os vários nutrientes na Vila de Pontal do Ribeira *

\begin{tabular}{l|c|c|c}
\hline Nutrientes & $\begin{array}{c}\text { Consumo médio } \\
\text { diário por pessoa }\end{array}$ & $\begin{array}{c}\text { Necessidade média } \\
\text { diária por pessoa }\end{array}$ & $\begin{array}{c}\text { Porcentagem de } \\
\text { adequą̧ão }\end{array}$ \\
\hline Calorias & 2229 & 2249 & 99 \\
Proteínas g & 65 & 53 & 123 \\
Vitamina A mg & 204 & 1375 & 15 \\
Vitamina C mg & 36 & 51 & 71 \\
Niacina mg & 13,2 & 14.9 & 89 \\
Vitamina B mg & 0,7 & 1,3 & 64 \\
Vitamina B mg & 0.7 & 1.1 & 20 \\
Cálcio mg & 190 & 945 & $\mathbf{5}$ \\
Fósforo mg & 1017 & 944 & 69 \\
Ferro mg & 9.3 & 13,4 &
\end{tabular}

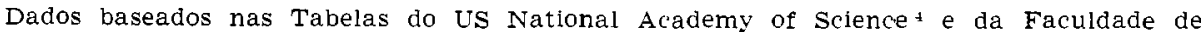
Saúde Pública da USP ${ }^{5}$

O grupo 5 (cereais e farinhas) representa $60 \%$ do valor calórico total da dieta nas duas comunidades. Dentro desses $60 \%$, a farinha de mandioca contribui com 50 e $64 \%$ e o arroz. 38 e $33 \%$, respectivamente, para a população de Icapara e de Pontal do Ribeira.

A farinha de mandioca, de preparação caseira, destaca-se como alimento hahi- tual. sendo utilizada pela quase totalidade das famílias residentes nas duas vilas estudadas, alcançando valores médios de ingestão bastante expressivos. A maioria das famílias usa a farinha de mandioca como substituto do pão. $\mathrm{O}$ arroz é o $2 .^{\circ}$ alimento de uso habitual, quer na quantidade diária ingerida, quer na percentagem de famílias que o consumiram (Tabela 1 ). 
MAZZILLI, R.N. - Algumas consideraçōes sobre o consumo de alimentos em Icapara e Pontal de Ribeira, São Paulo, Brasil. Rev. Saúde públ., S. Paulo, 9:49-55, 1975.

Entre as gorduras, a banha de porco e o óleo foram os tipos mais comuns. Nas duas localidades, do total consumido de gordura, a banha figurou com 78 e o óleo com $22 \%$.

Os grupos de alimentos que apresentaram menor consumo foram: os produtos lácteos, as hortaliças, as frutas e os feculentos frescos. 0 único tipo de leite consumido foi o em pó, empregado apenas na alimentação de crianças até um ano de idade; aquelas acima dessa idade não o recebiam. Comparando-se o consumo de leite de Icapara e Pontal com o de Iguape, pôde-se verificar que nesta última localidade o consumo é maior, principalmente do leite fresco. Enquanto que em Icapara e Pontal não foi ingerido o leite "in natura" e o leite em pó não chegou a 1 g diária "per capita", em Iguape o "per capita" diário de leite fresco foi de $35 \mathrm{ml}$ e de leite em pó, $5 \mathrm{~g}$.

O consumo maior de leite "in natura" pelas famílias de Iguape, quando comparado com as outras duas localidades, pode ser atribuído à maior facilidade de transporte entre a fonte fornecedora e o local consumidor.

As hortaliças e as frutas foram utilizadas por poucas famílias e sempre em quantidades pequenas. Esse fato leva-nos a concluir que entre essas populações não é hábito o cultivo de hortas nem do plantio de árvores frutíferas que permitam um consumo regular desses alimentos. As árvores de frutas lá existentes eram de baixa qualidade, o que não estimulava o consumo de seus produtos.

Das hortaliças consumidas, podemos citar: tomate, chuchu, abóbora, pepino, palmito, couve-flor, repolho, espinafre e alface, sempre em quantidades inexpressivas. Entre as frutas, o consumo restringiu-se à banana, fruta do conde, mamão e laranja, também em quantidades pequenas (Tabela 1), não contribuindo, assim, para que seja alcançada a taxa diária recomendada de vitaminas e de minerais, a qual pode- ria ser proporcionada através desses alimentos.

0 café e o açúcar são de uso generalizado. Houve somente uma família em Pontal que consumiu infusão de cevada em substituição ao café.

Pela análise do consumo de alimentos, verifica-se que a alimentação, nessas vilas, apresenta deficiência em cálcio, vitaminas $A, B_{1}, B_{2}$ e $C$ (Tabelas 2 e 3 ), decorrentes do baixo consumo dos alimentos considerados mais importantes no fornecimento desses nutrientes, como o leite, os ovos, as hortaliças e as frutas.

Na população de Pontal, a adequação do ferro observada em torno de $65 \%$ (Tabela 2) talvez se deva ao consumo menor do feijão, uma das principais fontes desse nutriente. Em Icapara, já se verificou adequação maior em relação ao ferro, sendo o consumo do feijão o dobro da quantidade ingerida pela população de Pontal. Essa inadequação de ferro poderia ter contribuído para a maior incidência de anemia ferropriva verificada por Szarfarc ${ }^{3}$ nas duas localidades em crianças menores de 10 anos.

A proteína, deficiente na alimentação da maioria das populações dos países em desenvolvimento, não representou problema, quando se considerou o consumo médio diário "per capita" nas duas vilas. Se considerarmos separadamente as famílias, verificamos que apenas 10,4 e $7,1 \%$ delas, respectivamente em Icapara e Pontal, apresentaram adequação protéica abaixo de $60 \%$; acima de $90 \%$ de adequação, 73,6 e $66,1 \%$, respectivamente, nas vilas de Icapara e Pontal.

A proteína animal que constitui problema alimentar de muitas populações, pelo alto custo dos alimentos que a fornecem, fez parte da alimentação de todas as famílias de Icapara: em $61 \%$ delas, o consumo médio por pessoa variou de 21 a $64 \mathrm{~g}$. Em $27,6 \%$ das famílias, encontramos ingestão abaixo de $20 \mathrm{~g}$ por dia de proteína animal. Na vila de Pontal, somente uma 
MAZZILLI. R.N. - Algumas consideragoes sobre o consumo de alimentos em Icapara e Pontal de Ribeira, São Paulo, Brasil. Rer. Saúle públ., S. Paulo, 9:49-55, 1975.

família não ingeriu proteína animal durante o período do levantamento; $8.9 \%$ das famílias consumiram proteína animal ahaixo de $20 \mathrm{~g}$ por dia. Entre 21 a $64 \mathrm{~g}$ encontramos $71.3 \%$ das famílias.

0 alimento responsável pelo alto teor de proteína animal na alimentação das duas populações estudadas foi o peixe. uma rez que são comunidades litorâneas que rivem da pesca.

As populações estudadas apresentaram. pois. alimentação deficitária em ritaminas e minerais. nutrientes esses que poderiam ser ohtidos através do cultivo mais generalizado de hortaliças e de árrores frutíferas de melhor qualidade. Entretanto. somente o incentivo à cultura de hortas domésticas não ajudará efetivamente a solução do problema: será necessário motirar o consumo desses alimentos. levando a cabo programas regulares e contínuos de educação nutricional.

\section{CONCLLSŌES E RECONIENDAÇŌES}

Dos dados obtidos através do inquérito alimentar realizado em Icapara e Pontal, conclui-se que:

- O total calórico diário foi satisfatório. predominando. principalmente, os hidratos de carbono na alimentação.

- Do grupo de cereais, a farinha de mandioca e o arroz foram os alimentos que deram maior contribuição ao contingente calórico.

- A taxa de proteína total foi adequada. bem como a de proteína animal, garantida pelo alto consumo de peixe verificado entre as famílias durante a realização do inquérito.

- O teor de cálcio foi baixo. principalmente pela falta de consumo de leite e de hortaliças.

- A ingestão de vitaminas $A, B_{1} . B_{\text {. }}$ e C foi deficiente. pelo escasso consumo dos alimentos veiculadores desses nutrientes.

- $O$ estudo dos hábitos alimentares das populações estudadas levaram-nos ao melhor conhecimento de suas preferências alimentares. informaçōes essas que poderão ser aproveitadas como subsídios para a orientação de programas integrados de nutrição. adequados às necessidades e aos recursos locais.

- Para melhorar o estado nutricional desse grupo etário no periodo após o desmame poderia ser feita uma campanha esclarecedora da importância do peixe como alimento fundamental em todas as idades. incluindo as crianças a partir de utm ano. Por tahu alimentar. as mães não dão peixe às crianças com menos de 4 anos de idade. A eliminação desse tabu viria melhorar sohremaneira a alimentação do pré-escolar.

- $O$ incentivo a um consumo maior de ovas. considerando a disponihilidade em virtude do elevado consumo de peixe, e tamhém de ovos, através da criação regular de aves proporcionará maior taxa daquelas vitaminas e do ferro. nutrientes esses carentes na alimentação local.

- O cultivo da horta e do pomar domiciliares ajudará a sanar as outras deficiências encontradas. Para combater a deficiência do cálcio, seria necessário solucionar o problema do leite, ou incentivando o comércio local com as comunidades próximas que têm acesso a esses produtos. ou mesmo através da criação de cabras orientada e inspecionada pela Divisão da Produção Animal da Secretaria da Agricultura.

- A melhoria do padrão alimentar da população das vilas estudadas será possível com a implantação de programa integrado de nutrição. colaborando as Secretarias da Agricultura, da Saúde e da Educação. através das respectivas unidades locais. 
MAZZILLI, R.N. - Algumas consicierações sobre o consumo de alimentos em Icapara e Pontal de Ribeira, São Paulo, Brasil. Rer. Saúde pübl., S Paulo, 9:49-55, 1975.

MazzILli, R. N. - [Consideration on food intake in Icapara and Pontal de Ribeira, State of S. Paulo, Brazil.] Rev. Saúde públ., S. Paulo, 9:49-55, 1975 .

SUMMARY: The dietary survey carried out among 105 familles from Icapara, and 56 from Pontal (Region of the Ribeira River Valley, state of S. Paulo, Brazil) showed some nutritional deficiencies. The food intake of 2 : hours was obtained by applying the method of direct weighing combined with the recall method. Foodstuffs of greater consumption were: cassava flour, fish and polished rice. The inadequacy of diet as regards some nutrients, such as vitamin $A$, thiamine, riboflavin, vitamin $C$ and Calclum, is connected with food habits. These populations rarely include milk, vegetables or frut in their dally diet. Animal protein was not a problem in the studied communities because fish was greatly consumed. An integrated program of Nutrition and Health Education is fundamental to improve dietary and social standards in these populations.

Uniterms: Dletary survey. Food intake. S. Paulo, Brazil.

\section{REFERENCIAS BIBLIOGRAFICAS}

1. ENCICLOPEDIA DOS MLXICAPIOS BRASILEIROS - Rio de Janeiro, IBGE. 1958 , v. 28.

2. STARE, F.J. - Why the science of nutrition? Nutr. Rev 8:1-5, 1950.

3. SZARFARC, S.C. - Anemia ferropriva da regiăo sul do estado de São Paulo Rev. Salide pübl, S. Paulo. 6:125-33. 1972 .

4. U S. NATIONAL ACADEMY OF SCIENCES - Recomended dietary allowan- ces: report $7^{\text {th }}$ ed Washington. D.C. 1968.

5. LNIVERSIDADE DE SAO PALLO. Faculdade de Saúde Pública Departamento de Nutrição - Tabela da composicrio quimica dos alimentos: Compilaça de várias tabelas nacronais e estrangeiras. São Paulo, 1971. [Mimeografado].

Recebido para publicação em 16-12-i4 Aprovado para publicasio em 13-01-is 